\title{
EVENTOS SECOS E CHUVOSOS NA BACIA HIDROGRÁFICA DO RIO PARAÍBA DO SUL: VARIABILIDADE ESPAÇO-TEMPORAL E TENDÊNCIA
}

\author{
GILDO RAFAEL DE ALMEIDA SANTANA, M.Sc. | IFF \\ VICENTE DE PAULO SANTOS DE OLIVEIRA, Dr. | IFF \\ JADER LUGON JÚNIOR, Dr. | IFF \\ MARIA GERTRUDES ALVAREZ JUSTI DA SILVA, Dra.| UENF
}

\section{RESUMO}

Os registros de ocorrência de eventos extremos de precipitação, seja por excesso ou déficit, mostram como a população, em geral, está suscetível aos danos causados por esses fenômenos. No campo ou na cidade, os desastres naturais são responsáveis por danos econômicos, materiais e humanos e, dependendo da vulnerabilidade da comunidade, esses danos podem ser catastróficos. O objetivo deste trabalho foi estudar e caracterizar os extremos de precipitação (déficit ou excesso) na Bacia Hidrográfica do Rio Paraíba do Sul.

\section{MÉTODO}

Para isso, foram utilizados dados de precipitação de 88 postos pluviométricos, para o período de 1970 a 2018. Neste estudo, os eventos extremos de precipitação (déficit ou excesso) foram caracterizados pelo Índice Padronizado de Precipitação, na escala de 12 meses (SPI12). Para detectar tendências estatisticamente significativas, utilizou-se o teste estatístico não paramétrico de Mann-Kendall. A magnitude das tendências foi obtida pelo estimador de Sen.

\section{RESULTADOS}

A partir das séries temporais do SPI-12, identificou-se que os eventos de déficit e excesso de precipitação mais severos e de maior abrangência espacial, ocorridos entre 1970 a 2018, foram registrados em 2014 (73,0\% da área) e 1983 (77,5\% da área), respectivamente. Com relação a localização exata (área) da bacia atingida por cada um dos eventos mais severos e de maior abrangência espacial, destaca-se a região norte da bacia por ser a mais atingida pelos eventos secos. Na análise de tendência das séries anuais de precipitação, as maiores magnitudes positivas (acima de $9 \mathrm{~mm} / \mathrm{ano}$ ) foram observadas em Areal-RJ, Patrocínio do Muriaé-MG, Jussara-MG, Carangola-MG e Fazenda São João-SP. Nas magnitudes negativas, destacam-se as registradas em Vigário Descarga D'água-RJ (-38,88mm/ano) e Alto S. do Mar-B Mato Limpo-SP (-32,78mm/ano), por apresentarem elevadas taxas de diminuição. De modo geral, os resultados obtidos sinalizam que o regime pluviométrico na Bacia do Rio Paraíba do Sul vem sofrendo alterações locais, apresentando tendência significativa (ao nível de confiança de 95\%) positiva em 5 postos pluviométricos e negativa em 6 postos, ou seja, em algumas regiões os totais de precipitação vêm diminuindo e em outras vêm aumentando. Assim, este estudo assinala para a importância do monitoramento hidrológico pontual e regional. Espera-se que os resultados obtidos neste estudo possam subsidiar ações de planejamento e gestão hídrica e ambiental, visando reduzir a vulnerabilidade aos danos causados pela ocorrência de eventos extremos de precipitação na área de estudo.

\section{REFERÊNCIAS}

SANTANA, G. R. A. Eventos Secos e Chuvosos na Bacia HidrográficadoRioParaíbadoSul:VariabilidadeEspaçoTemporal e Tendência. Dissertação (Curso de Pósgraduação em Engenharia Ambiental) Instituto Federal Fluminense, Macaé. 2021. Disponível em: http://portal1.iff.edu.br/pesquisa-e-inovacao/pos-graduacao-stricto-sensu/mestrado-em-engenharia-ambiental/ dissertacoes-de-mestrado/2021 
